nephron

Practice
Nephron

DOI: $10.1159 / 000450893$
Received: June 30, 2016

Accepted after revision: September 19, 2016

Published online: October 21, 2016

\title{
Glomerular Filtration Rate in Healthy Living Potential Kidney Donors: A Meta-Analysis Supporting the Construction of the Full Age Spectrum Equation
}

\author{
Hans Pottel $^{a}$ Liesbeth Hoste ${ }^{a}$ Eric Yayo ${ }^{c}$ Pierre Delanaye ${ }^{b}$ \\ ${ }^{a}$ Department of Public Health and Primary Care, KU Leuven Campus Kulak, Kortrijk, and bephrology-Dialysis-

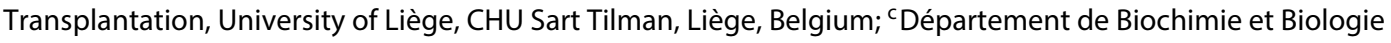 \\ Moléculaire, UFR Sciences Pharmaceutiques, Université Felix Houphouët-Boigny, Abidjan, Côte d'Ivoire
}

\section{Key Words}

Renal function $\cdot$ Healthy subjects $\cdot$ Aging $\cdot$ Glomerular filtration rate prediction equation

\begin{abstract}
Background: Normal kidney function or, more specifically, normal glomerular filtration rate (GFR) in men and women and its decline with age is still much debated today. The Chronic Kidney Disease Epidemiology Collaboration (CKD$\mathrm{EPI}$ ) equation has gender (and race) multiplication factors, accounts for a decline that starts at very young age and assumes that the mean GFR is as high as $120-130 \mathrm{ml} /$ $\mathrm{min} / 1.73 \mathrm{~m}^{2}$ from a young age. The full age spectrum (FAS) estimated mean GFR is about $107 \mathrm{ml} / \mathrm{min} / 1.73 \mathrm{~m}^{2}$ at a young age and remains constant until the age of 40 years and then starts to decline both in men and women. The aim of this research study was to give more insight into 'normal' GFR levels and the physiological decrease of kidney function with age and to use a meta-analysis to evaluate the mathematical construction of the FAS and the CKD-EPI equation. Methods: We conducted a meta-analysis of published GFR measurements in healthy Caucasian living potential kidney donors $(\mathrm{n}=$ $5,482,46.8 \%$ men). Only publications dating from 2000 were selected to avoid the possible influence of body surface area changes in the last decades on the indexed GFR, expressed in $\mathrm{ml} / \mathrm{min} / 1.73 \mathrm{~m}^{2}$. Results: We found that the mean GFR $\approx$
\end{abstract}

$107 \mathrm{ml} / \mathrm{min} / 1.73 \mathrm{~m}^{2}$ up to the age of 40 years, but renal decline begins beyond 40 years. No evidence could be found for any difference between men and women in the separate age groups. Conclusions: The current meta-analysis supports the mathematical form of the FAS equation, which matches the age/sex dependency of measured GFR for healthy potential living kidney donors.

(c) 2016 S. Karger AG, Basel

\section{Introduction}

Defining normal kidney function is certainly a difficult task in nephrology. Indeed, renal function is a vast concept, which can be approached in several different ways. Glomerular filtration rate (GFR) is considered as one important parameter to assess global kidney function $[1,2]$. Definition of normal kidney function implies that GFR is measured with high precision. However, direct measurement of GFR is not so easy in daily practice and most nephrologists refer to estimated GFR (eGFR), that is, equations based on biomarkers like serum creatinine (Scr) or plasma cystatin C [3-5]. Another difficulty with GFR is the fact that GFR physiologically decreases with aging. In other words, the 'normal' thresholds of GFR are obviously different at 40 versus 80 years [1,6-8]. Relatively few studies have been published where measured GFR

\section{KARGER}

(C) 2016 S. Karger AG, Basel

E-Mail karger@karger.com

www.karger.com/nef
Prof. Dr. Hans Pottel

Department of Public Health and Primary Care KU Leuven Campus Kulak

Etienne Sabbelaan 53, BE-8500 Kortrijk (Belgium)

E-Mail Hans.Pottel@kuleuven-kulak.be 
Fig. 1. PRISMA flow diagram.

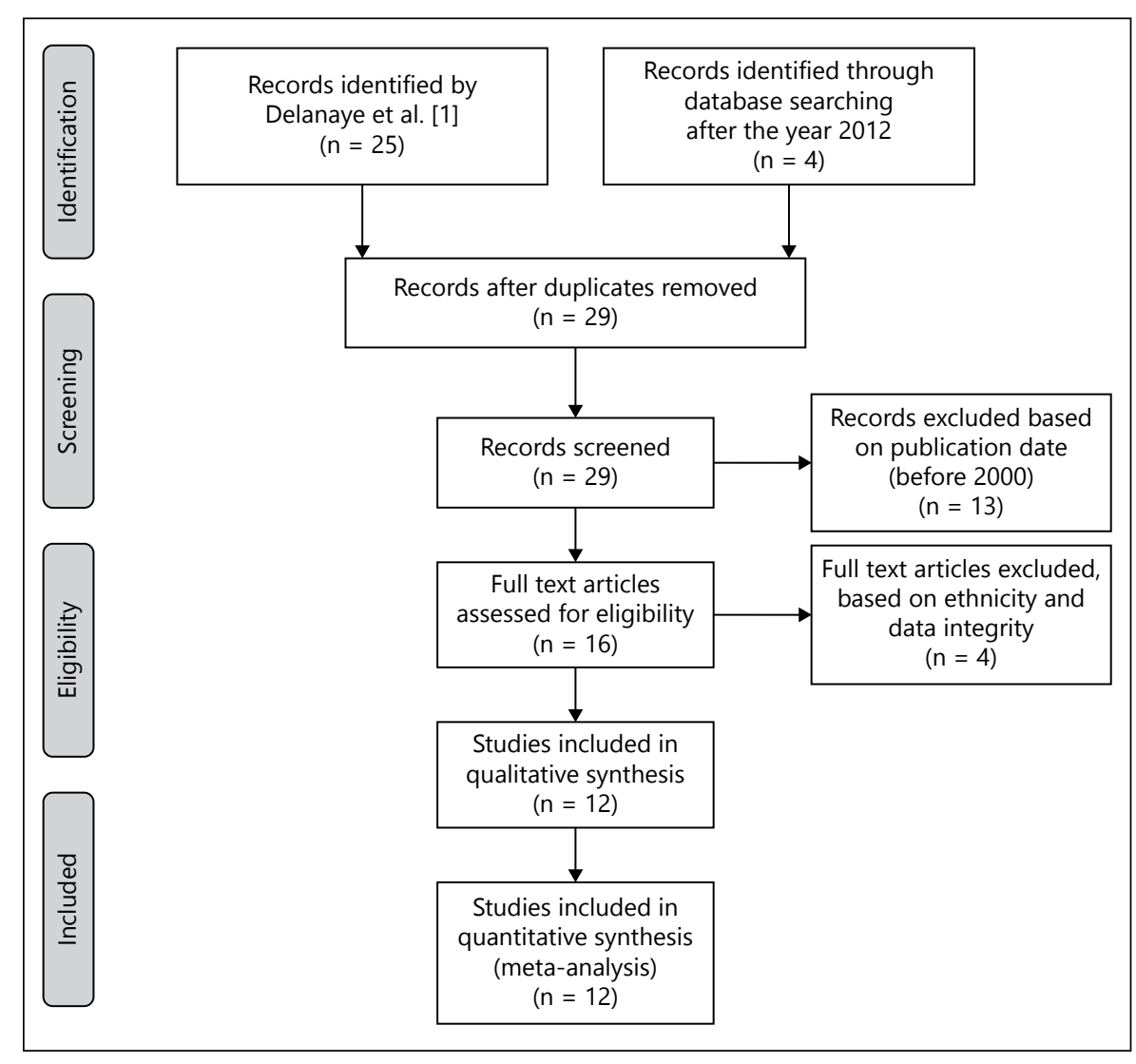

(mGFR) has been obtained in healthy subjects and, in vast majority of these studies, the samples remain relatively modest [6,9-20]. We thus believe there is a place for a meta-analysis on this topic, focusing on key points which remain controversial in the literature: what is 'normal' GFR? Is 'normal' GFR different in men and women? When does the physiological decrease in GFR begin? All these questions are also of importance to evaluate and compare the construction of the recommended Chronic Kidney Disease Epidemiology Collaboration (CKD-EPI) equation [4] and the new full age spectrum (FAS) equation [21], which was recently proposed to estimate GFR across the entire age spectrum from 2 to old age (FAS$\mathrm{eGFR}=107.3 /(\mathrm{Scr} / \mathrm{Q}) \times 0.988^{(\text {age-40)}}$ when age $>40$ years $)$, where $\mathrm{Q}$ is the median Scr concentration for healthy agematched subjects $(0.90 \mathrm{mg} / \mathrm{dl}$ for men and $0.70 \mathrm{mg} / \mathrm{dl}$ for women). Indeed, the FAS equation and CKD-EPI equation clearly differ in mathematical construction. The FAS equation implies that (i) mean GFR of healthy subjects aged between 18 and 40 years is approximately $107 \mathrm{ml} /$ $\mathrm{min} / 1.73 \mathrm{~m}^{2}$ and not decreasing from around 125 (at 18 years) to $107 \mathrm{ml} / \mathrm{min} / 1.73 \mathrm{~m}^{2}$ (at 40 years), as predicted by CKD-EPI, (ii) GFR is not different in men and women, thus, no gender multiplication factor at the GFR level is required and (iii) decline in GFR only begins at 40 years and not already at the age of 18 years, as built in the mathematical construction of the CKD-EPI equation [21]. Moreover, this decline rate is faster in FAS (as expressed by $0.988^{\text {age }}$ ) than in the CKD-EPI equation (as expressed by $\left.0.993^{\text {age }}\right)$.

To answer these much-debated questions, we present a meta-analysis summarizing mGFR data from all currently available relevant studies in healthy living potential kidney donors, allowing for a more comprehensive understanding of the differences between men and women and the evolution of mean GFR of healthy subjects with aging.

\section{Materials and Methods}

\section{Search Strategy}

The review article of Delanaye et al. [1] listed studies of sufficient size and representative of the general population for which the healthy status of the sample was unquestionable, and where the method used to measure GFR was accurate and the statistical assessment adequate $(n=25$; fig. 1$)$. These studies were here identified for the current meta-analysis. Using the search terms 'GFR' 
and 'living kidney donors', we searched PubMed/MEDLINE and Web of Science (Web of Knowledge) databases between the year 2000 up to November 2015 and additionally identified 4 studies published after 2012 (the publishing date of the Delanaye review) presenting mGFR in living potential kidney donors (fig. 1).

Two contributing authors (H.P. and P.D.) considered and selected studies as potentially eligible for our meta-analysis by independently reviewing the titles and abstracts of each study identified by the search and then examining the full text. We resolved any disagreement regarding whether a particular study should be included using discussion among all of the contributing authors, followed by a consensus reached by all.

\section{Inclusion and Exclusion Criteria}

Only publications written in English and dating from after the year 2000 were selected to avoid the possible influence of body surface area (BSA) changes in the last decades on the indexed GFR, expressed in $\mathrm{ml} / \mathrm{min} / 1.73 \mathrm{~m}^{2}$ [9]. Based on that criterion, 13 studies were excluded (fig. 1). More recent studies presented lower mGFR values as normal compared to prior studies published in the 1950s or before. This observation is explained by the BSA adjustment as BSA has been increased significantly during the last 3 decades and the BSA-unadjusted GFR did not show such a decrease $[9,22]$.

Only publications involving white and Arabic (Caucasian) living potential kidney donors were selected, because it is suspected that normal GFR could be different according to ethnicity, especially in Asian people [1]. We also excluded abstracts and studies that did not allow the retraction of numbers, mean GFRs and SDs from the published text. Based on these 2 criteria, 4 studies were excluded (fig. 1). Finally, 12 articles were involved in the metaanalysis (fig. 1). For each article, male and female data were presented separately, which leads to a maximum of $2 \times 12=24$ 'studies' used in this meta-analysis.

\section{Outcome Measures}

We retrieved measured mean GFR $\left(\mathrm{ml} / \mathrm{min} / 1.73 \mathrm{~m}^{2}\right)$, SD, age group, sex and numbers of men/women in each age group. SD was sometimes obtained from 2.5 th or 5 th percentile to 95 th or 97.5th percentile, using $\mathrm{SD}=(\mathrm{Pct} 2.5-\mathrm{Pct} 97.5) / 4$ or $\mathrm{SD}=(\mathrm{Pct} 5-$ Pct95)/3.29. We defined age groups as decades: 20-30, 30-40, 40$50,50-60,60-70$ and $\geq 70$ years, but when case data were not available from these decades, we shifted by maximum 5 years to match the predefined age groups.

\section{Data Extraction}

Two contributing authors (H.P. and L.H.) independently extracted the data from the full text and partitioned the numbers into age groups. Any disagreement between the 2 authors was resolved by discussion. For the outcomes of GFR, relevant group means (SD) per age group were extracted from each included study, by inspecting the tables or figures or by reading the text. When mean GFR and/or numbers for men and women were not available from the tables, we made a reasonable estimate from the figures (for mGFR, and by counting subjects, where possible for men and women) and tried to assign correct numbers to age groups for men/women, as much as possible. In case the numbers for men or women were simply not available, neither from tables nor inspection of figures nor by reading the text, we equally distributed men and women among age groups, a subjective decision which we only applied in very few cases, as described in table 1.

Meta-Analysis in Kidney Donors

\section{Statistical Analysis}

All statistical analyses were performed in MS Excel using a selfwritten macro in Visual Basic for Applications (online suppl. material; for all online suppl. material, see www.karger.com/ doi/10.1159/000450893), after the theory outlined by Lipsey and Wilson [23]. Continuous outcomes were analyzed using mean differences and SDs.

Effect sizes for the difference between sexes were calculated along with 95\% CIs using a fixed effect model. We assumed that the effect sizes differ only because of sampling error, because we rule out the differences between studies by defining the effect size as the difference between mGFR for both sexes, divided by the pooled $\mathrm{SD}$, and thus the effect size from each study estimates a single common mean. Effect sizes differ from each other because each study used a different sample of participants.

A random-effects model was used to determine the overall mean mGFR and 95\% CIs for the means. A random-effects model assumes a genuine diversity in the results of the included studies due to between-study heterogeneity and incorporates a between-study variance (random effect) into the calculation accordingly.

Between-study heterogeneity was evaluated using the $\chi^{2}$ test based on the Cochran's Q statistic, and an $\mathrm{I}^{2}$ index was used for assessing heterogeneity, in which an $\mathrm{I}^{2}$ value of 25,50 or $75 \%$ represented low, moderate or high heterogeneity, respectively. p < 0.05 was considered statistically significant, although correction for multiple comparisons is considered during the discussion.

We also investigated the relationship between the outcome mean mGFR and the covariates 'study', 'sex', 'age-group' and 'method' with a weighted generalized linear model (GLM).

\section{Results}

\section{Eligible Studies and Study Characteristics}

Table 1 gives an overview of the studies and the way we obtained mean GFR, SD and numbers for men and women from the 12 selected publications [6, 9-16, 24-26].

\section{Extracted Data from the Selected Studies}

Table 2 gives a detailed overview of the data for mean GFR, SD and numbers of men and women per age group, as we extracted them from these publications. A total of 5,482 (2,565 men and 2,917 women) living kidney donors, who were subdivided to 104 sub-studies (per age group and gender), were involved in this meta-analysis. The data from table 2 were used to answer the research questions of interest.

\section{Is There a Difference between Men and Women in Each Age Group?}

We subdivided each publication into a study for men and women as we wanted to evaluate the difference in mean GFR between sexes. The results of this fixed-effects meta-analysis are summarized in table 3 . Heterogeneity 
Table 1. List of studies included in this meta-analysis and description of the methods used to extract the relevant data. The table and figure numbering refers to the corresponding reference

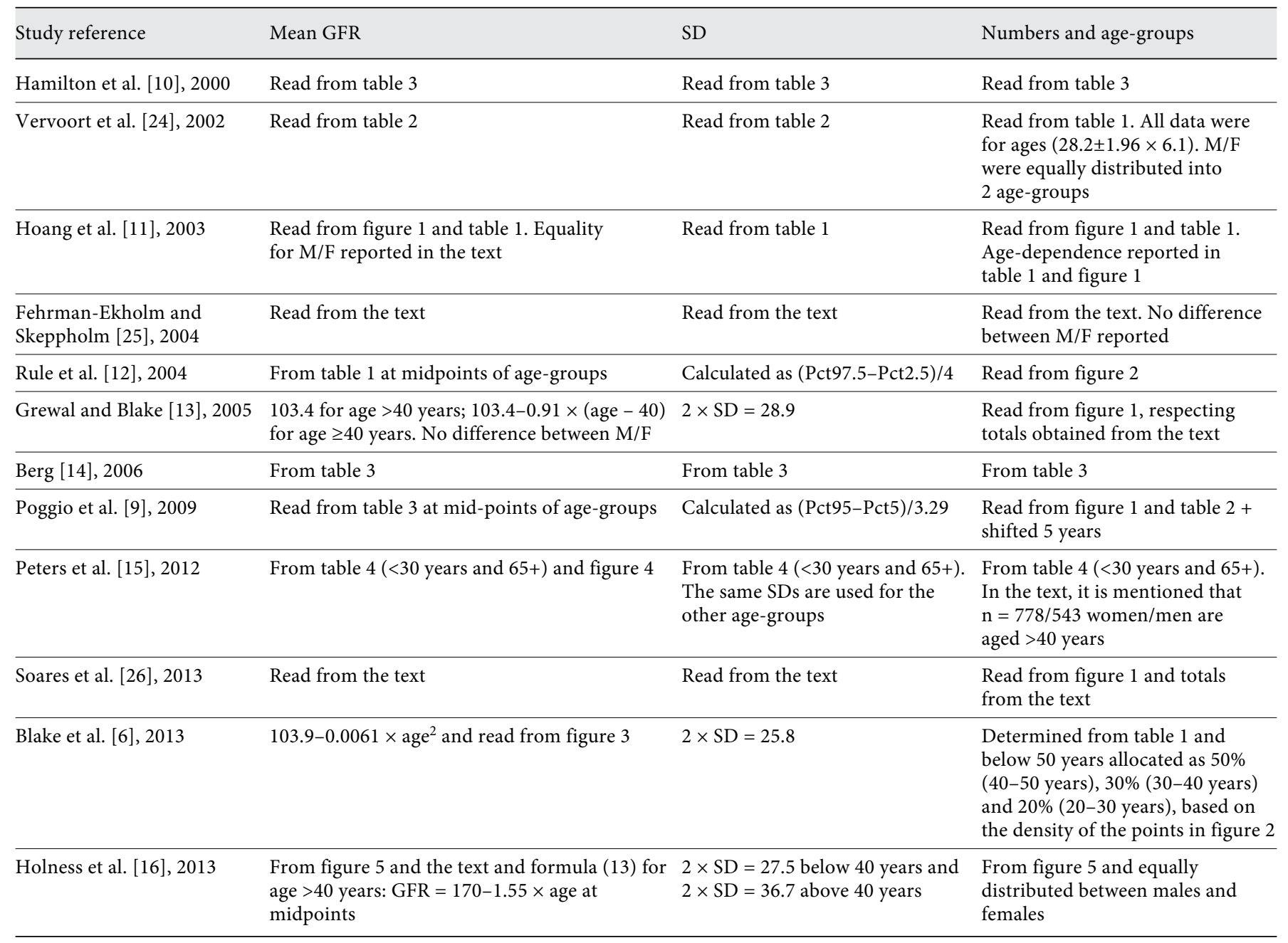

Pct $=$ Percentile; $M=$ male; $F=$ female .

$\left(\mathrm{I}^{2}\right)$ between studies is presented for information only and was low to moderate. Up to the age of 50 years, there is no difference between men and women (effect sizes are not different from zero). Above 50 years, there is a tendency for a difference of about $3.5 \mathrm{ml} / \mathrm{min} / 1.73 \mathrm{~m}^{2}$, with a faster renal decline in women than in men. For the age group $\geq 70$ years, only 3 studies had a small number of subjects and none of these studies reported mean mGFRs for men and women separately.

\section{What Is the Mean GFR in Each Age Group?}

To answer this research question, we performed a meta-analysis to estimate the mean GFR in the different age groups. The results of the random-effects model are summarized in table 4. Forest plots (fig. 2-6) show the mean mGFR with $95 \%$ CIs for the mean for each study, separate for men and women, together with the final mean mGFR (and 95\% CI) obtained from the metaanalysis random-effects model. For each age group, large heterogeneity between the studies was observed. Figures 2 and 3 also show the mean mGFR $=107.3 \mathrm{ml} /$ $\mathrm{min} / 1.73 \mathrm{~m}^{2}$ (vertical line) predicted from the FAS equation and the possible CKD-EPI predictions (shaded area) for the average healthy adult $<40$ years (corresponding with $\mathrm{Scr}=0.90 \mathrm{mg} / \mathrm{dl}$ for males and $0.70 \mathrm{mg} / \mathrm{dl}$ for $\mathrm{fe}-$ males). When the vertical line crosses the horizontal 95\% CIs, this indicates that there is no statistically significant difference between the study results and the 
Table 2. Data extracted from the selected studies in order of appearance

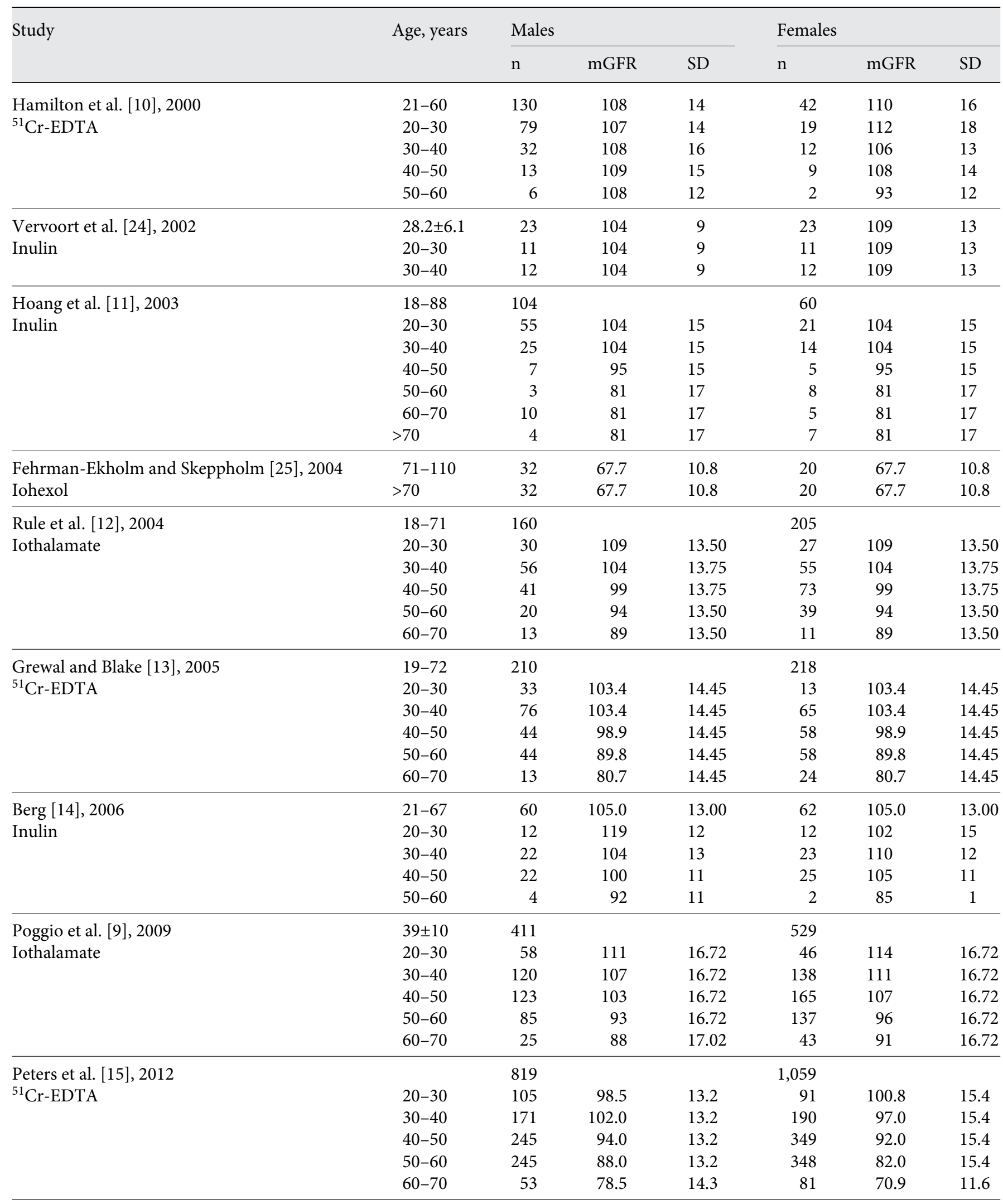


Table 2. (continued)

\begin{tabular}{|c|c|c|c|c|c|c|c|}
\hline \multirow[t]{2}{*}{ Study } & \multirow[t]{2}{*}{ Age, years } & \multicolumn{3}{|c|}{ Males } & \multicolumn{3}{|c|}{ Females } \\
\hline & & $\mathrm{n}$ & mGFR & SD & $\mathrm{n}$ & mGFR & SD \\
\hline \multirow[t]{4}{*}{${ }^{51} \mathrm{Cr}-\mathrm{EDTA}$} & $20-30$ & 28 & 113 & 18 & 36 & 111 & 18 \\
\hline & $30-40$ & 29 & 113 & 18 & 37 & 111 & 18 \\
\hline & $40-50$ & 28 & 101 & 16 & 37 & 96 & 14 \\
\hline & $60-70$ & 6 & 101 & 16 & 9 & 96 & 14 \\
\hline Blake et al. [6], 2013 & $18-84$ & 436 & & & 468 & & \\
\hline \multirow[t]{3}{*}{${ }^{51} \mathrm{Cr}-\mathrm{EDTA}$} & $20-30$ & 65 & 104 & 12.9 & 63 & 101 & 12.9 \\
\hline & $30-40$ & 98 & 97 & 12.9 & 98 & 99 & 12.9 \\
\hline & $40-50$ & 163 & 92 & 12.9 & 154 & 93 & 12.9 \\
\hline Holness et al. [16], 2013 & $18-59$ & 57 & 107 & 14.9 & 69 & 100.7 & 17.9 \\
\hline \multirow[t]{4}{*}{${ }^{99 \mathrm{~m}} \mathrm{Tc}-\mathrm{DTPA}$} & $20-30$ & 21 & 108.0 & 13.75 & 32 & 108.0 & 13.75 \\
\hline & $30-40$ & 15 & 108.0 & 13.75 & 15 & 108.0 & 13.75 \\
\hline & $40-50$ & 17 & 100.3 & 18.35 & 17 & 100.3 & 18.35 \\
\hline & $50-60$ & 4 & 84.8 & 18.35 & 5 & 84.8 & 18.35 \\
\hline
\end{tabular}

$\mathrm{n}=$ Number of subjects.

Table 3. Meta-analysis results for comparing mean GFR between men and women

\begin{tabular}{llrrrrrr}
\hline $\begin{array}{l}\text { Age group, } \\
\text { years }\end{array}$ & \#Studies & \#M & \#F & $\mathrm{I}^{2}$ (\%; p value) & $\begin{array}{l}\text { Standardized effect } \\
\text { size (95\% CI) }\end{array}$ & $\begin{array}{c}\mathrm{p} \text { value } \\
\text { Effect size (95\% CI), } \\
\mathrm{ml} / \mathrm{min} / 1.73 \mathrm{~m}^{2}\end{array}$ \\
\hline $20-30$ & $11 / 12$ & 497 & 371 & $33.1(0.134)$ & $-0.03(-0.16$ to 0.11$)$ & 0.714 & $-0.4(-2.3$ to 1.6$)$ \\
$30-40$ & $11 / 12$ & 656 & 659 & $49.4(0.032)$ & $0.00(-0.11$ to 0.11$)$ & 0.969 & $0.0(-1.5$ to 1.6$)$ \\
$40-50$ & $10 / 12$ & 703 & 892 & $22.3(0.238)$ & $-0.01(-0.11$ to 0.09$)$ & 0.831 & $-0.1(-1.6$ to 1.3$)$ \\
$50-60$ & $10 / 12$ & 514 & 750 & $50.0(0.035)$ & $0.23(0.12$ to 0.35$)$ & 0.0001 & $3.4(1.7$ to 5.1$)$ \\
$60-70$ & $7 / 12$ & 157 & 206 & $22.6(0.257)$ & $0.25(0.04$ to 0.47$)$ & 0.020 & $3.7(0.6$ to 6.9$)$ \\
$>70$ & $3 / 12$ & 38 & 39 & $0.0(1.000)$ & $0.00(-0.48$ to 0.48$)$ & 1.000 & $0.0(-6.7$ to 6.7$)$ \\
Total & & 2,565 & 2,917 & & & &
\end{tabular}

\#Studies $=$ The number of studies or articles involved in the hypothesis of equality (out of 12 selected articles). $\mathrm{I}^{2}(\mathrm{p}$ value) $=$ measure of homogeneity among studies, with p indicating Cochran's Q significance. Standardized effect size $=$ difference in mean mGFR between males (\#M) and females (\#F) divided by the pooled SD. 95\% CI for the effect size. $p=p$ value for testing the hypothesis of equality of mean mGFR between sexes. Effect size = GFR-difference corresponding to the standardized effect size expressed in $\mathrm{ml} / \mathrm{min} / 1.73 \mathrm{~m}^{2}$.

mean mGFR of $107.3 \mathrm{ml} / \mathrm{min} / 1.73 \mathrm{~m}^{2}$. For subjects $>40$ years, the grey-shaded areas in figures 4-6 indicate the areas of possible FAS (or CKD-EPI) predictions for that age interval (for the same Scr values). Overlap with the 95\% CIs of the studies indicates no statistically significant difference.

\section{When Does Renal Function Start to Decline?}

The selected studies for the age groups 20-30 and 3040 years were the same, which allowed us to test equality of mean GFR between these age groups, controlling for study and sex. The overall effect size was 0.12 with $95 \%$ CI $0.03-0.21(\mathrm{p}=0.012)$ indicating that there is a slight sta- 
Table 4. Meta-analysis results for mean GFR, CKD-EPI and FAS estimation in $\mathrm{ml} / \mathrm{min} / 1.73 \mathrm{~m}^{2}$

\begin{tabular}{lccccc}
\hline Age group, years & \#Studies & CKD-EPI & FAS & Mean mGFR & $95 \%$ CI \\
\hline $20-30$ & $22 / 24$ & $114-125$ & 107.3 & 106.7 & $104.6-108.9$ \\
$30-40$ & $22 / 24$ & $107-117$ & 107.3 & 104.9 & $102.8-107.0$ \\
$40-50$ & $20 / 24$ & $99-109$ & $95-107$ & 99.0 & $96.5-101.6$ \\
$50-60$ & $18 / 24$ & $93-101$ & $84-95$ & 90.7 & $88.1-93.3$ \\
$60-70$ & $14 / 24$ & $86-95$ & $75-84$ & 84.0 & $79.5-88.5$ \\
$>70$ & $6 / 24$ & $70-88$ & $52-75$ & 69.4 & $66.1-72.7$ \\
\hline
\end{tabular}

$\mathrm{I}^{2}>75 \%$ in all age-groups, indicating that high heterogeneity among studies was observed. \#Studies $=$ The number of studies involved in the meta-analysis for the corresponding age-group (out of $12 \times 2=24$ male/ female datasets). CKD-EPI and FAS = eGFR-prediction range for the corresponding age-group. 95\% CI for the mean mGFR.

tistically significant but clinically meaningless difference of $1.8 \mathrm{ml} / \mathrm{min} / 1.73 \mathrm{~m}^{2}$ between the mean GFR of both age groups; however, when correcting for multiple comparisons, this $\mathrm{p}$ value turns into a non-significant difference.

With the only exception of the study by Vervoort et al. [24], all studies for the age groups 30-40 and 40-50 years were the same, which allowed us again to test the equality of mean GFR between these age groups. The overall effect size was 0.39 (95\% CI of $0.31-0.47 ; \mathrm{p}<0.0001)$ indicating that there was a strong statistically significant (and clinically relevant) difference of $5.9 \mathrm{ml} / \mathrm{min} / 1.73 \mathrm{~m}^{2}$ between the mean GFR of both age groups.

All studies for the age groups 40-50 years were compared with the age groups 50-60 years yielding an overall effect size of 0.53 with $95 \%$ CI of $0.45-0.61$ ( $p<0.0001$ ) indicating that the decrease accelerates as mean mGFR is significantly different $\left(7.8 \mathrm{ml} / \mathrm{min} / 1.73 \mathrm{~m}^{2}\right)$ from the previous age group with a larger effect size.

Finally, the comparison between age groups 50-60 and 60-70 years (for all studies, except for Vervoort et al. [24], Hamilton et al. [10], Berg [14] and Holness et al. [16] who did not have kidney donors in the last age group) gives an overall effect size of 0.55 with $95 \%$ CI of $0.42-0.67$ ( $p<0.0001$ ) corresponding to a difference of $8.2 \mathrm{ml} /$ $\mathrm{min} / 1.73 \mathrm{~m}^{2}$ indicating that the decrease goes on at the same rate.

\section{Sensitivity Analysis}

We performed a sensitivity analysis, leaving out one study (both men and women) at a time to evaluate the influence of one particular study on the overall results. In the age groups $20-30,30-40,50-60$ and $60-70$ years, the largest influence was obtained from the study of Peters et al. [15], with a significant decrease in heterogeneity $\mathrm{I}^{2}$ when omitted. In the age group of 40-50 years, the study of Poggio et al. [9] showed the largest influence, and when omitted, heterogeneity $\mathrm{I}^{2}=90.3 \%$ decreased to $82.2 \%$. The sensitivity analysis raised the question whether there was an effect of the method used.

\section{Is There an Effect of the Method Used?}

This question is difficult to answer without the individual patient data. However, we realized that most of the studies were obtained with ${ }^{51} \mathrm{Cr}$-EDTA $(50 / 104=48.1 \%)$, followed by inulin $(24 / 104=23.1 \%)$, iothalamate $(20 / 104=19.2 \%),{ }^{99 m}$ Tc-DTPA $(8 / 104=7.7 \%)$ and iohexol $(2 / 104=1.9 \%)$. We performed a fixed-effect analysis in each age group for the ${ }^{51} \mathrm{Cr}$-EDTA studies, the inulin studies and the iothalamate studies, pooling studies on men and women (table 5).

The mean GFRs obtained in each age group by ${ }^{51} \mathrm{Cr}-$ EDTA are significantly lower than those obtained with iothalamate. In 2 age groups, ${ }^{51} \mathrm{Cr}$-EDTA is also significantly lower than the inulin reference method. The conclusion is that there is a significant difference between GFR methods with underestimation for ${ }^{51} \mathrm{Cr}$-EDTA and overestimation of iothalamate compared to the inulin reference method.

\section{Meta-Regression}

A weighted GLM (weights were defined as $\mathrm{w}_{\mathrm{i}}=1$ / $\left(\mathrm{SD}_{\mathrm{i}}{ }^{2} / \mathrm{n}_{\mathrm{i}}\right)$ ) explains $99 \%$ of the variation in $\mathrm{mGFR}$, with 'age group', 'study' and the interaction term 'age group' $\times$ 'study' explaining, respectively, $50.3,42.0$ and $4.3 \%$ of the variation in mGFR. This reflects the age decline of $m G F R$ and the heterogeneity between the studies at hand. 'Sex' only explained $0.5 \%$ of the total variation and the interaction terms 'study' $\times$ 'sex' and 'sex' $x$ 'age' only contributed 1.5 and $0.5 \%$ to the explained variation, respectively, confirming that there is no difference between men and 


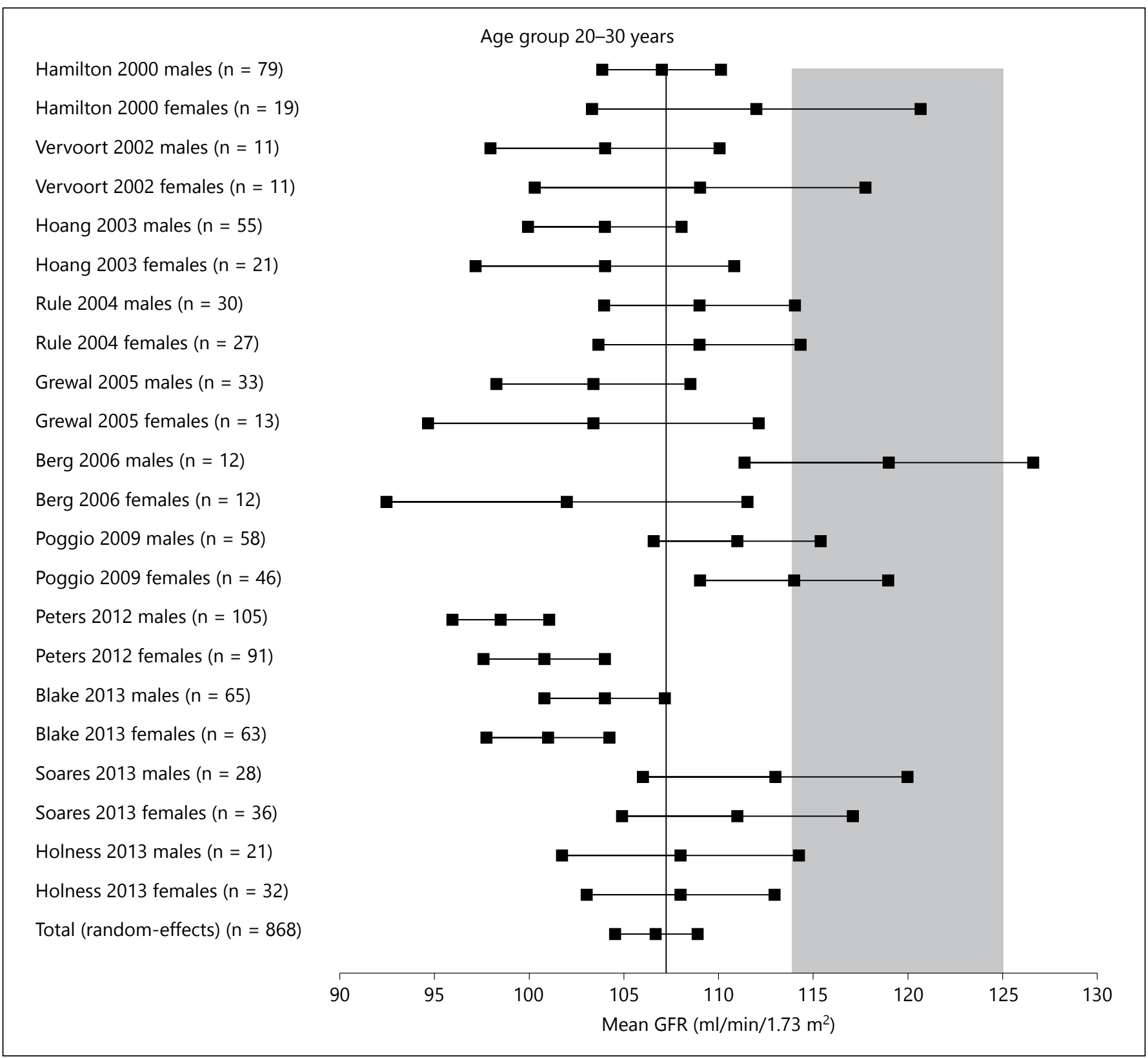

Fig. 2. Forest plot for the age group 20-30 years. The vertical black line gives the FAS prediction for the mean GFR of $107.3 \mathrm{ml} /$ $\mathrm{min} / 1.73 \mathrm{~m}^{2}$, corresponding to $\mathrm{Scr}=0.90 \mathrm{mg} / \mathrm{dl}$ for men and 0.70 $\mathrm{mg} / \mathrm{dl}$ for women, the median Scr values for healthy Caucasian people. The grey-shaded region gives the possible CKD-EPI predictions $\left(114-125 \mathrm{ml} / \mathrm{min} / 1.73 \mathrm{~m}^{2}\right)$ for this age group, for the same Scr values. women in the different age groups. If we replaced 'study' by 'method', the model still explained $88 \%$ of the total variation in mGFR, with 'age group' (59\%) and 'method' (26\%) as the only significant variables in the model. In this model, no significant interaction terms were observed. This confirms that the measurement method has an important effect on the reported mGFR values.

\section{Publication Bias}

The danger of unsystematic reviews, with only a portion of relevant studies included, is that they could introduce (publication) bias. One simple way of assessing the likely presence of publication bias is to examine a funnel plot $[27,28]$. An asymmetric funnel indicates a relationship between effect size and precision in the 


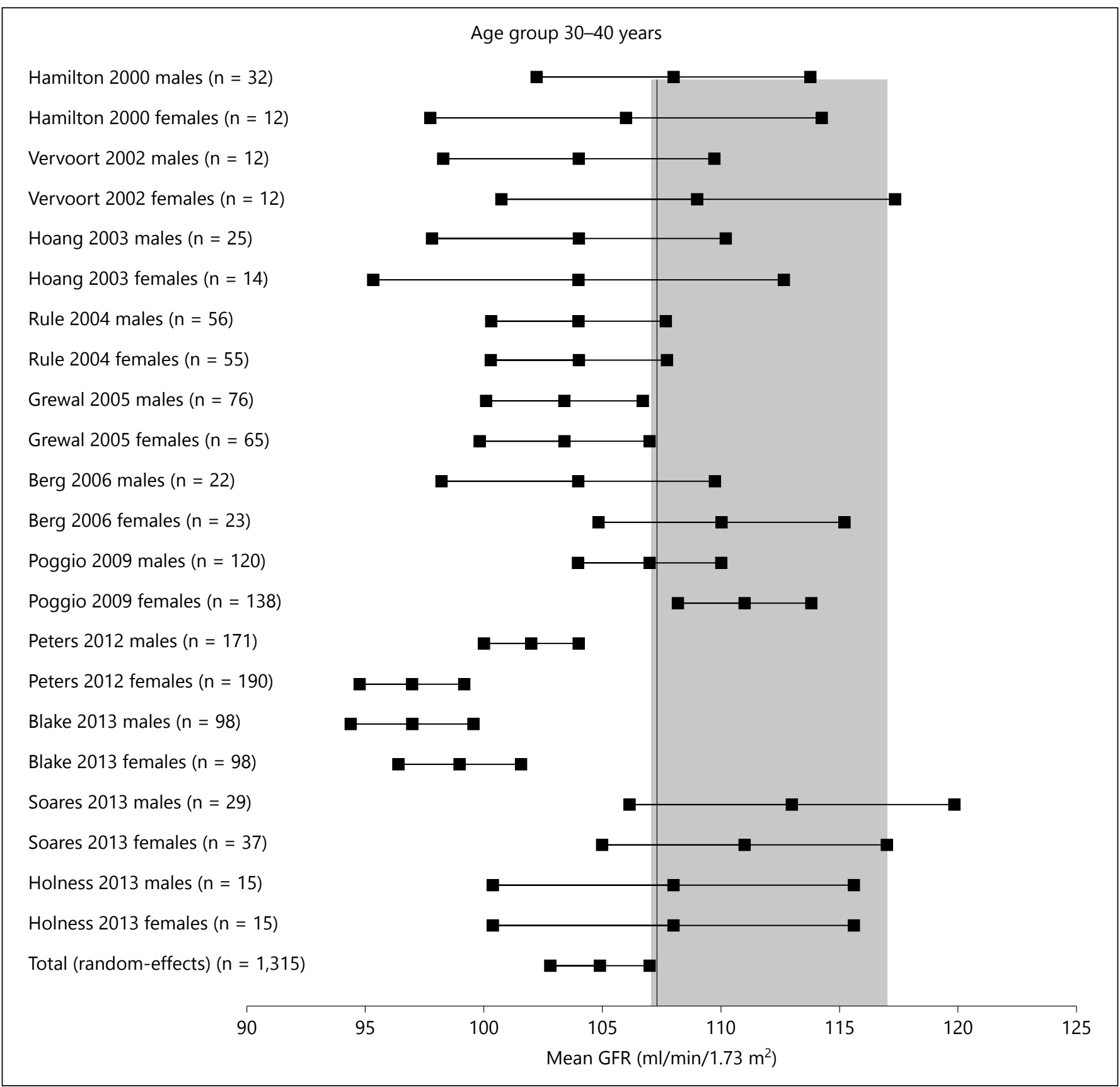

Fig. 3. Forest plot for the age group 30-40 years. The vertical line represents the FAS prediction for the mean GFR of $107.3 \mathrm{ml} /$ $\mathrm{min} / 1.73 \mathrm{~m}^{2}$, corresponding to $\mathrm{Scr}=0.90 \mathrm{mg} / \mathrm{dl}$ for men and 0.70 $\mathrm{mg} / \mathrm{dl}$ for women, the median Scr values for healthy Caucasian people. The grey-shaded region gives the possible CKD-EPI predictions $\left(107-117 \mathrm{ml} / \mathrm{min} / 1.73 \mathrm{~m}^{2}\right.$ ) for this age-group, for the same Scr values. studies at hand. The funnel plots (online suppl. material) for each age group up to 50 years for the difference between men and women were not asymmetric. However, beyond 50 years, the number of studies rapidly decreased and the funnel plots became asymmetric, a sign of a possible publication bias or the shift to positive effect sizes for the studies still present may also indicate a more rapid decline of the renal function in women compared to men. 
Age group $40-50$ years

Hamilton 2000 males $(n=13)$

Hamilton 2000 females $(n=15)$

Hoang 2003 males ( $n=7$ )

Hoang 2003 females $(n=5)$

Rule 2004 males $(n=41)$

Rule 2004 females ( $n=73$ )

Grewal 2005 males $(n=44)$

Grewal 2005 females $(n=58)$

Berg 2006 males $(n=22)$

Berg 2006 females $(n=25)$

Poggio 2009 males $(n=123)$

Poggio 2009 females $(n=165)$

Peters 2012 males $(n=245)$

Peters 2012 females $(n=349)$

Soares 2013 males $(n=28)$

Soares 2013 females $(n=37)$

Blake 2013 males $(n=163)$

Blake 2013 females $(n=154)$

Holness 2013 males $(n=17)$

Holness 2013 females $(n=17)$

Total (random-effects) $(n=1,595)$

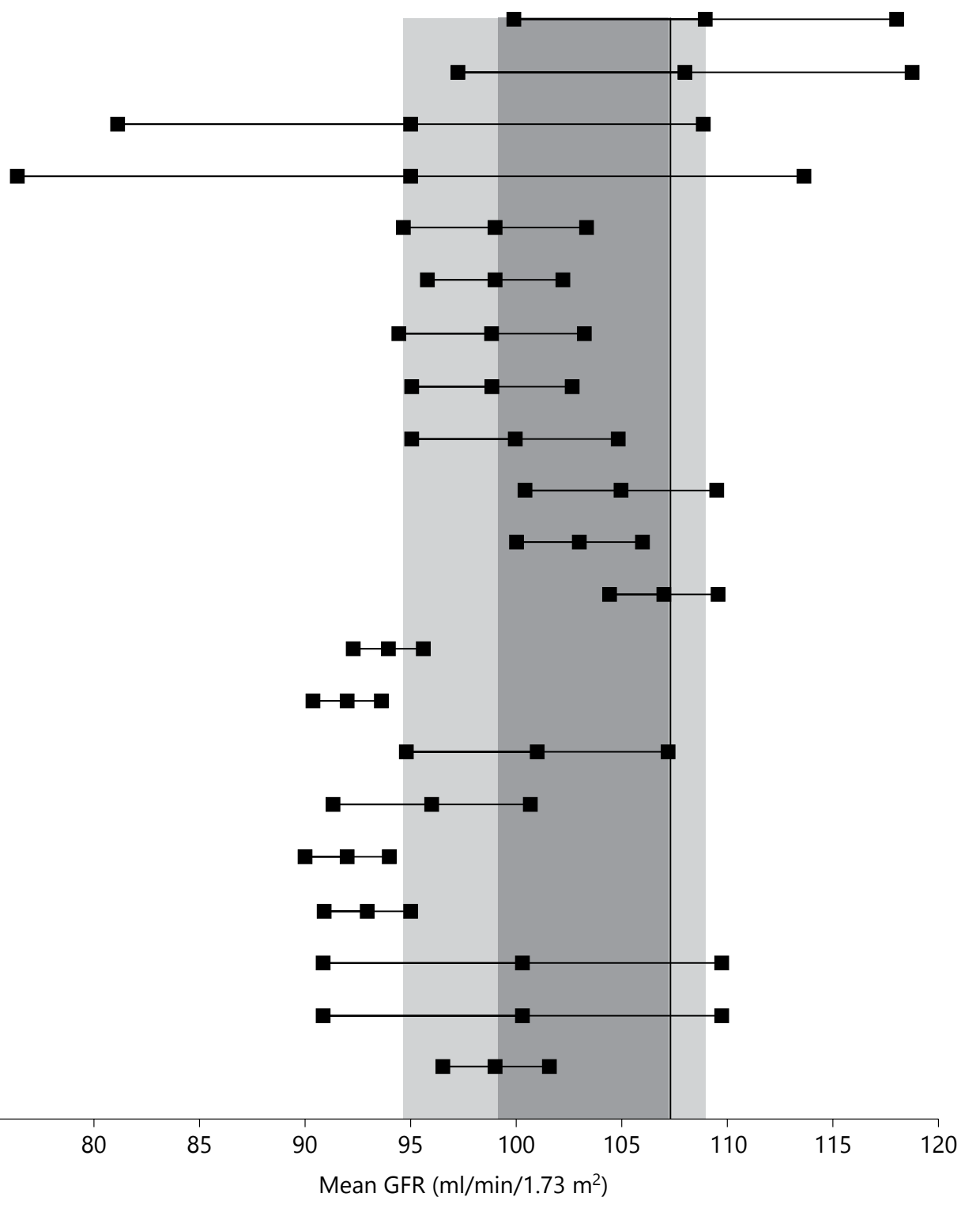

Fig. 4. Forest plot for the age group 40-50 years. The grey areas give the range of mean GFR values $95-107$ predicted by the FAS equation and by the CKD-EPI equation 99-109 for this age group,

\section{Discussion}

In the current meta-analysis, we confirmed several important facts regarding normal GFR. First, normal GFR is around $107 \mathrm{ml} / \mathrm{min} / 1.73 \mathrm{~m}^{2}$, both in men and women, until 40 years and at this age, the mean GFR value tends to decrease progressively. The mean GFR of 107 for the median Scr values for healthy Caucasian people. The vertical line represents the FAS prediction of $107.3 \mathrm{ml} / \mathrm{min} / 1.73 \mathrm{~m}^{2}$ up to the age of 40 years.
10

Nephron

DOI: $10.1159 / 000450893$ $\mathrm{ml} / \mathrm{min} / 1.73 \mathrm{~m}^{2}$ was first suggested by original data obtained by Piepsz et al. $[29,30]$ from children in 2006. The results of our meta-analysis (data from 12 selected articles) confirm that mGFR in adults aged between 20 and 30 years is well (or at least not different from) 107 $\mathrm{ml} / \mathrm{min} / 1.73 \mathrm{~m}^{2}$. For subjects aged between 30 and 40 years, the mean mGFR was only slightly significantly dif- 


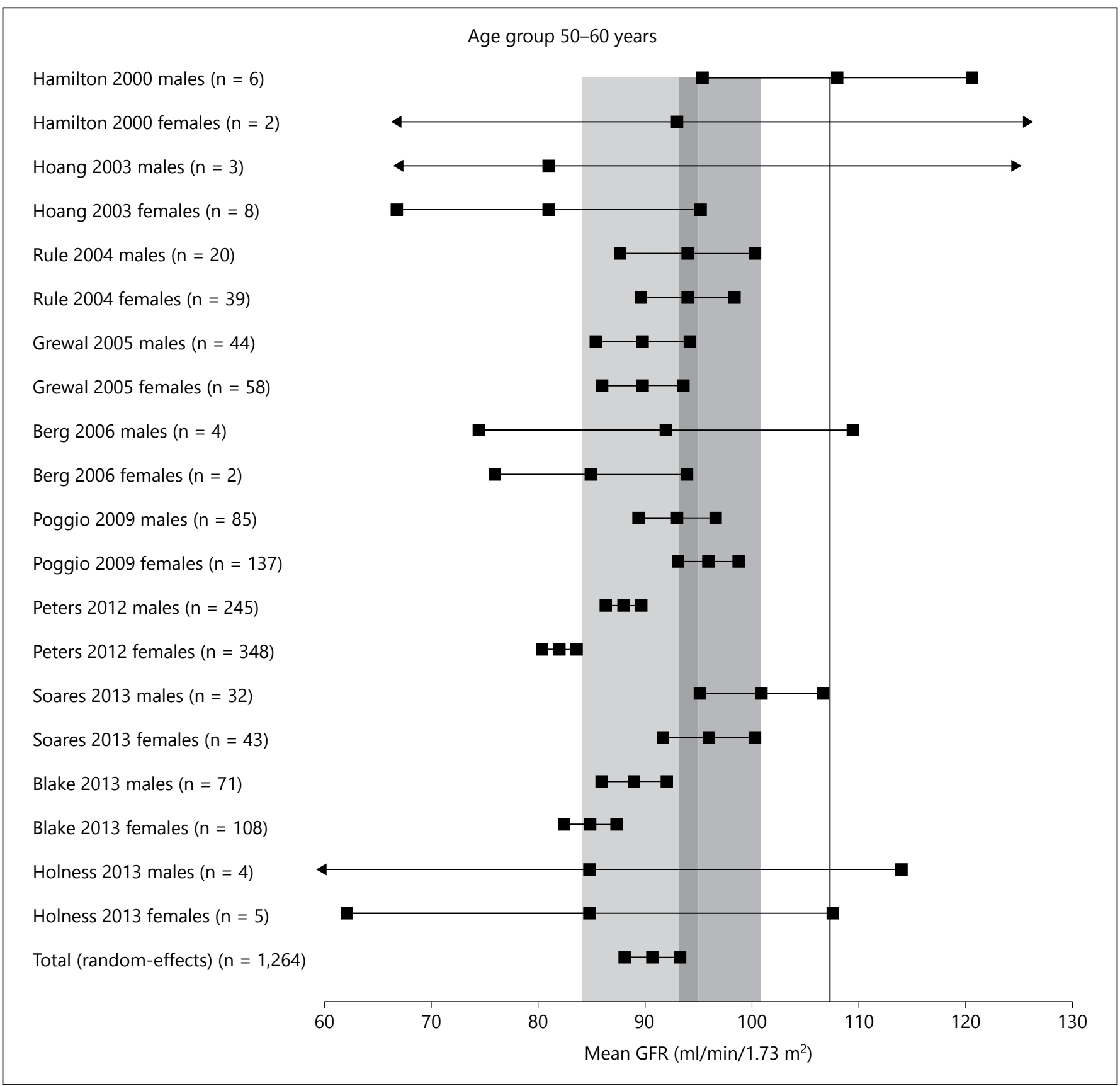

Fig. 5. Forest plot for the age-group 50-60 years. The grey areas give the range of mean GFR values $84-95$ predicted by the FAS equation and by the CKD-EPI equation 93-101 for this age group, for the median Scr values for healthy Caucasian people. The vertical line represents the FAS prediction of $107.3 \mathrm{ml} / \mathrm{min} / 1.73 \mathrm{~m}^{2}$ up to the age of 40 years. ferent from $107 \mathrm{ml} / \mathrm{min} / 1.73 \mathrm{~m}^{2}$ but this difference is clearly not relevant from a clinical point of view, as the mean mGFR was $104.9 \mathrm{ml} / \mathrm{min} / 1.73 \mathrm{~m}^{2}$. Moreover, the study by Peters et al. [15] has the largest impact (weight) on the meta-analysis results, since this is the study with the largest number of subjects, but at the same time, this study consistently showed the lowest mean mGFR values for all age groups. Without the Peters data, the mean mGFR in the 30-40 years age group becomes 105.6 with a $95 \%$ CI of 103.4-107.8, which includes 107.3 $\mathrm{ml} / \mathrm{min} / 1.73 \mathrm{~m}^{2}$. This mean of $107.3 \mathrm{ml} / \mathrm{min} / 1.73 \mathrm{~m}^{2}$ is exactly the GFR value predicted by the FAS equation at 


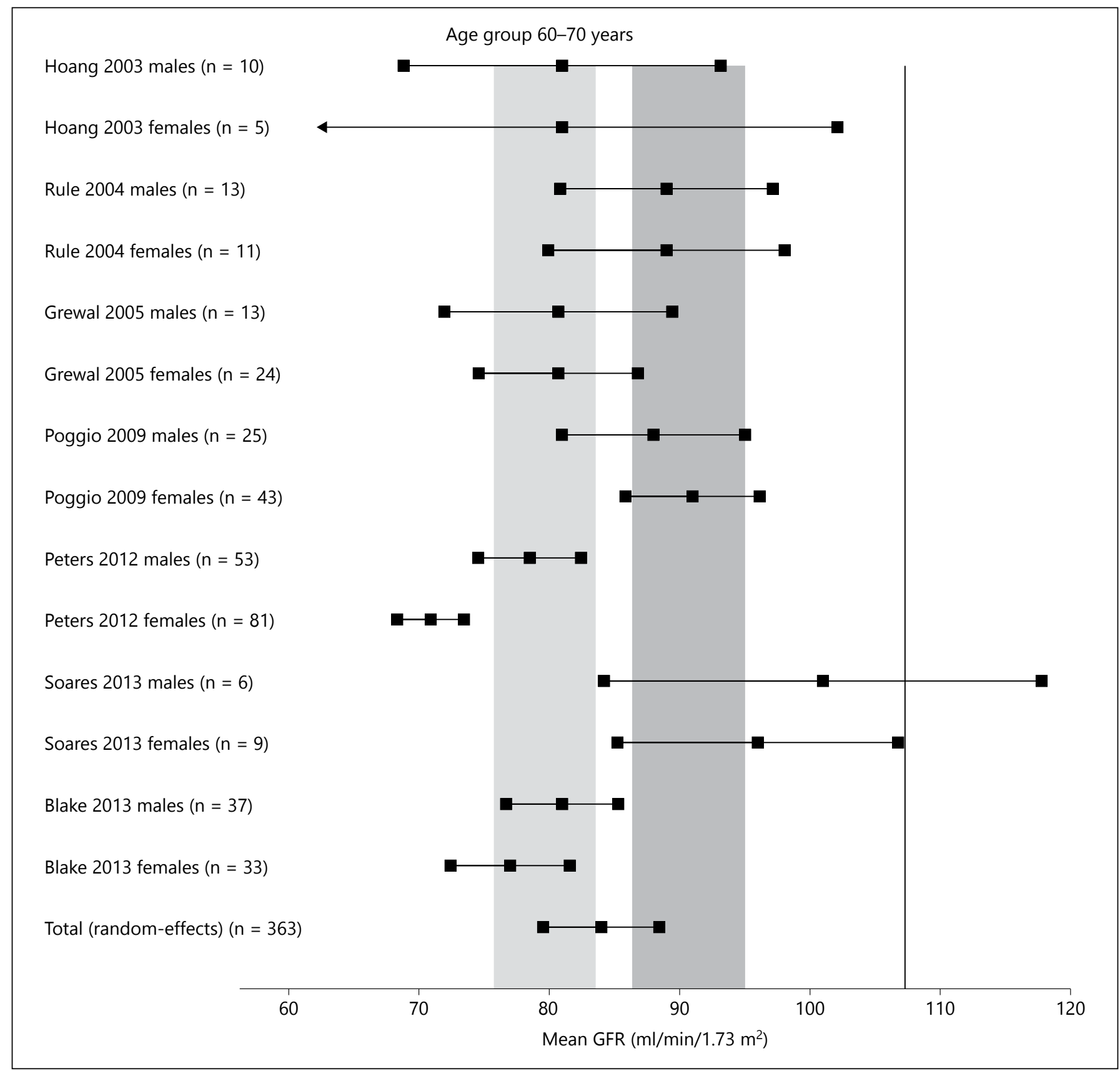

Fig. 6. Forest plot for the age group 60-70 years. The grey areas give the range of mean GFR values $75-84$ predicted by the FAS equation and by the CKD-EPI equation $86-95$ for this age group, for the median Scr values for healthy Caucasian people. The vertical line represents the FAS prediction of $107.3 \mathrm{ml} / \mathrm{min} / 1.73 \mathrm{~m}^{2}$ up to the age of 40 years.
$\mathrm{Scr}=0.70 \mathrm{mg} / \mathrm{dl}$ (women) and Scr $=0.90 \mathrm{mg} / \mathrm{dl}$ (men), the median Scr values for healthy Caucasian people [21]. These results of the meta-analysis support the construction of the FAS equation. On the other hand, the mean GFR predicted by the CKD-EPI equation for the average healthy adult subject $(\mathrm{Scr}=\mathrm{Q})$ evolves from 122.5 (men) and $125.1 \mathrm{ml} / \mathrm{min} / 1.73 \mathrm{~m}^{2}$ (women) at the age of 20 years to 106.5 (men) and $108.7 \mathrm{ml} / \mathrm{min} / 1.73 \mathrm{~m}^{2}$ (women) at the age of 40 years, a difference of $13 \%$. The high values of about $120-125 \mathrm{ml} / \mathrm{min} / 1.73 \mathrm{~m}^{2}$ at young adult age and the decline of about $13 \%$ are not supported by the findings of the current meta-analysis results. 
Table 5. Meta-analysis results for the mean mGFR and 95\% CIs per age group for the different mGFR methods

\begin{tabular}{lccc}
\hline Age, years & ${ }^{51}$ Cr-EDTA & Inulin & Iothalamate \\
\hline $20-30$ & $103.0(101.8-104.2)^{\mathrm{a}}$ & $106.2(103.8-108.6)$ & $110.8(108.4-113.2)^{\mathrm{a}}$ \\
$30-40$ & $100.8(99.9-101.8)^{\mathrm{a}, \mathrm{b}}$ & $105.9(103.6-108.3)^{\mathrm{a}}$ & $107.1(105.6-108.7)^{\mathrm{b}}$ \\
$40-50$ & $93.9(93.0-94.7)^{\mathrm{a}, \mathrm{b}}$ & $101.7(98.8-104.7)^{\mathrm{a}}$ & $103.0(101.4-104.5)^{\mathrm{b}}$ \\
$50-60$ & $86.9(86.0-87.8)^{\mathrm{a}}$ & $85.0(83.7-86.4)^{\mathrm{b}}$ & $94.6(92.8-96.5)^{\mathrm{a}, \mathrm{b}}$ \\
$60-70$ & $76.8(75.2-78.4)^{\mathrm{a}}$ & 81.0 & $89.6(86.4-92.8)^{\mathrm{a}}$ \\
\hline
\end{tabular}

a, b Same symbol denotes a statistically significant difference (at row level): for example, for the 20-30 years age group, 103.0 is significantly different from 110.8, but not from 106.2.

The second key message of our meta-analysis is that mean mGFR is not different between men and women, at least not before the age of 50 years $[9,31]$, and thus, there is no need to build in an extra multiplication factor for gender at the GFR level, when the correction for differences in Scr generation has already been done at the Scr level. At this point, we have to comment on the indexation by BSA. Indeed, if non-indexed GFR is considered, there is an expected difference of $\mathrm{mGFR}$ in men and women as body size is different according to gender. This point has been nicely illustrated in the RENIS cohort study [31]. Also, we and others have criticized the indexation of GFR by BSA. If indexation of mGFR is necessary when the GFR of one given subject needs to be compared with another one, using the BSA is certainly not the best physiological tool to index and other authors have proposed other variables like height or total body water $[22,31]$. However, we must admit that indexation by BSA is still the most used, both in clinical research and in daily practice. The BSA indexation is also included in data sets used to develop eGFR equations [4]. Moreover, the impact of BSA (or the errors induced by BSA indexation) will be clinically relevant only in very low and very high BSA values $[22,31]$. Because the subjects included from the 12 selected articles analyzed in this meta-analysis have normal or near normal BSA values, the absence of a difference in normal mGFR between men and women can be considered as a good reflection of reality. Berg [14] observed a faster decline rate in men than in women in the age range $20-50$ years, but not in the years beyond 50 years, which she explained as that women seemed to be protected in the pre-menopausal period, probably by estrogens. We did not observe a difference between men and women up to the age of 50 years, and beyond 50 years, the current meta-analysis showed a small $\left(3.5 \mathrm{ml} / \mathrm{min} / 1.73 \mathrm{~m}^{2}\right)$ but significant difference between men and women in the age groups 50-60 and 60-70 years with a faster decline in women than in men, a finding

Meta-Analysis in Kidney Donors also reported in a Brazilian [26] and a Chinese population [32]. Women seem to be no longer protected in the postmenopausal period. Clearly, these contradictory results need more investigation.

From this meta-analysis, we also confirmed data from several (but not all) studies suggesting that mGFR progressively declines from the age of 40 years $[2,11,13,17$, 20,33 . Indeed, we clearly showed that mGFR is not different in healthy subjects aged between 20 and 30 years on one side and between 30 and 40 years on the other side. Only after 40 years, the mGFR observed is significantly lower than in these youngest. This observation also justifies the mathematical construction of the FAS equation, which models the decline in GFR from 40 years on [21]. Indeed, the FAS equation does not predict a decline between 20 and 40 years. If we use the mean mGFR observed in this meta-analysis at the age of 35 years $(\mathrm{mGFR}=$ $\left.104.9 \mathrm{ml} / \mathrm{min} / 1.73 \mathrm{~m}^{2}\right)$ and at 75 years $(\mathrm{mGFR}=69.4 \mathrm{ml} /$ $\mathrm{min} / 1.73 \mathrm{~m}^{2}$ ), we can calculate the average $\mathrm{mGFR}$ decline. The mean GFR decline over this 40-year period is (69.4$104.9) / 40=-0.89 \mathrm{ml} / \mathrm{min} / 1.73 \mathrm{~m}^{2} /$ year. Over the same period and for mean normal Scr values, the FAS equation predicts an average decline rate of $(70.3-107.3) / 40=-0.92$ $\mathrm{ml} / \mathrm{min} / 1.73 \mathrm{~m}^{2} /$ year. These results are very close to each other, whereas the same calculation with the CKD-EPI equation will result in a decline of $(83.3-110.3) / 40=$ $-0.68 \mathrm{ml} / \mathrm{min} / 1.73 \mathrm{~m}^{2} /$ year (for men). This larger difference from the meta-analysis result can be explained by the fact that the CKD-EPI equation used a statistical model with a constant decline rate of GFR with aging over the 18-75 year age period. The alternative construction of the FAS equation shows no age dependency up to 40 years and a faster decline rate constant $\left(0.988^{\text {age }}\right)$ beyond that age. In other words, the CKD-EPI age term $\left(0.993^{\text {age }}\right)$ has to balance the different age decline rates of the 20-40 years versus the 40-75 years age range into one overall 'mean' decline rate factor. The age knot at 40 years is the most 
important difference between the FAS and CKD-EPI equations. The current independent meta-analysis supports the age-knotted form of the FAS equation.

mGFR can be obtained with different methods [34]. The gold standard method is the urinary clearance of inulin [2]. This method is however cumbersome and costly and other biomarkers like iothalamate, iohexol, ${ }^{51} \mathrm{Cr}$ EDTA and ${ }^{99}$ Tc-DTPA [34] can be used. Each marker, including inulin, can be used in different protocols with or without urine collections (i.e., plasma vs. renal clearance) [35]. All the biomarkers and most of the methods can be considered as 'reference method' [34]. However, the way GFR is measured in every single centre is unfortunately not standardized. Moreover, it is clear from the literature that each method can give slightly different results [34, 36, 37]. It is thus not surprising that we found different mGFR values according to the reference method considered in the present meta-analysis. Compared to inulin results, iothalamate clearances give higher mGFR values, which may also partially explain the higher estimations by CKDEPI (which was developed on iothalamate data). From the literature, this result is expected as it has been suggested that iothalamate is secreted by renal tubules, leading to a slight overestimation of GFR measured by inulin $[34,38]$, while results from studies using ${ }^{51} \mathrm{Cr}$-EDTA clearances give lower mGFR than inulin. Such observation was observed by pioneers in ${ }^{51} \mathrm{Cr}$-EDTA like BrochnerMortensen [39]. The differences observed between methods in the present meta-analysis must be interpreted very carefully. Indeed, because of the lack of standardization in measuring GFR, differences can be due not only because different filtration markers were used but also because of the methodology used to calculate GFR: plasma versus renal clearances, choice of sampling times, analytical methods to measure plasma levels etc. [34, 35, 37, 40]. The number of studies in the current meta-analysis is too low to consider all these potential methodological biases.

There are limitations to our meta-analysis. First, the populations concerned in the meta-analysis are, for the majority, subject candidates for living kidney donation. Sensu stricto, they can be considered as not equivalent to the normal general population. Second, the number of healthy subjects $>65$ years remains limited. We clearly need additional studies in this specific population. Third, we limited our meta-analysis to Caucasians. Some limited data from the literature suggest that normal mGFR in African subjects could be the same $[9,41]$ but a dedicated research in this population would be welcome as data are clearly lacking. Limited data are also available from Asian populations. Normal mGFR could be slightly lower in such Asian populations. Different hypotheses to explain such results are lower BSA in this population, low protein diet or different methods to measure GFR $[1,32,42$, 43]. Also in this population, additional research seems necessary. Fourth, all the studies included in this metaanalysis are cross-sectional. Therefore, the mean decline in $\mathrm{mGFR}$ in $\mathrm{ml} / \mathrm{min} / 1.73 \mathrm{~m}^{2} /$ year described here $(-0.89$ $\mathrm{ml} / \mathrm{min} / 1.73 \mathrm{~m}^{2} /$ year between 35 and 75 years), even if not very different from few available data in longitudinal studies, must be interpreted with caution [44-46]. Lastly, the current meta-analysis does not allow the investigation of the Scr dependency in the eGFR equations, which is also different between the FAS and CKD-EPI equations.

In conclusion, the current meta-analysis confirms that normal mean mGFR is the same in men and women, below the age of 50 years, is not different from the value of $107 \mathrm{ml} / \mathrm{min} / 1.73 \mathrm{~m}^{2}$ proposed from pediatric data up to the age of 40 years and starts to decline significantly beyond 40 years. This meta-analysis also underlines the necessity of future research in other ethnicities, in healthy subjects $>65$ years and in a longitudinal design. The results of the current meta-analysis also support the mathematical construction of the new FAS equation recently proposed to estimate GFR with a good precision and accuracy from infancy to older age [21].

\section{Disclosure Statement}

The authors declare no conflicts of interest.

\section{Statement of Ethics}

This retrospective study on anonymous data did not require informed consent nor review/approval by the appropriate ethics committee.

References
1 Delanaye P, Schaeffner E, Ebert N, Cavalier E, Mariat C, Krzesinski JM, Moranne O: Normal reference values for glomerular filtration rate: what do we really know? Nephrol Dial Transplant 2012;27:2664-2672.

2 Smith HW: The Kidney: Structure and Function in Health and Disease. New York, Oxford University Press, 1951.

3 Delanaye P, Mariat C: The applicability of eGFR equations to different populations. Nat Rev Nephrol 2013;9:513-522.

4 Levey AS, Stevens LA, Schmid CH, Zhang YL, Castro AF 3rd, Feldman HI, Kusek JW, Eggers P, Van Lente F, Greene T, Coresh J: A new equation to estimate glomerular filtration rate. Ann Intern Med 2009;150:604-612.
14 
5 Inker LA, Schmid CH, Tighiouart H, Eckfeldt JH, Feldman HI, Greene T, Kusek JW, Manzi J, Van Lente F, Zhang YL, Coresh J, Levey AS; CKD-EPI Investigators: Estimating glomerular filtration rate from serum creatinine and cystatin C. N Engl J Med 2012;367:20-29.

6 Blake GM, Sibley-Allen C, Hilton R, Burnapp L, Moghul MR, Goldsmith D: Glomerular filtration rate in prospective living kidney donors. Int Urol Nephrol 2013;45:1445-1452.

7 van den Brand JA, van Boekel GA, Willems HL, Kiemeney LA, den Heijer M, Wetzels JF: Introduction of the CKD-EPI equation to estimate glomerular filtration rate in a Caucasian population. Nephrol Dial Transplant 2011;26:3176-3181.

8 Baba M, Shimbo T, Horio M, Ando M, Yasuda Y, Komatsu Y, Masuda K, Matsuo S, Maruyama S: Longitudinal study of the decline in renal function in healthy subjects. PLoS One 2015;10:e0129036.

9 Poggio ED, Rule AD, Tanchanco R, Arrigain S, Butler RS, Srinivas T, Stephany BR, Meyer KH, Nurko S, Fatica RA, Shoskes DA, Krishnamurthi V, Goldfarb DA, Gill I, Schreiber MJ Jr: Demographic and clinical characteristics associated with glomerular filtration rates in living kidney donors. Kidney Int 2009;75: 1079-1087.

10 Hamilton D, Riley P, Miola U, Mousa D, Popovich W, al Khader A: Total plasma clearance of 51Cr-EDTA: variation with age and sex in normal adults. Nucl Med Commun 2000;21:187-192.

11 Hoang K, Tan JC, Derby G, Blouch KL, Masek M, Ma I, Lemley KV, Myers BD: Determinants of glomerular hypofiltration in aging humans. Kidney Int 2003;64:1417-1424.

12 Rule AD, Gussak HM, Pond GR, Bergstralh EJ, Stegall MD, Cosio FG, Larson TS: Measured and estimated GFR in healthy potential kidney donors. Am J Kidney Dis 2004;43:112-119.

13 Grewal GS, Blake GM: Reference data for 51Cr-EDTA measurements of the glomerular filtration rate derived from live kidney donors. Nucl Med Commun 2005;26:61-65.

14 Berg UB: Differences in decline in GFR with age between males and females. Reference data on clearances of inulin and PAH in potential kidney donors. Nephrol Dial Transpl 2006;21:2577-2582.

15 Peters AM, Perry L, Hooker CA, Howard B, Neilly MD, Seshadri N, Sobnack R, Irwin A, Snelling H, Gruning T, Patel NH, Lawson RS, Shabo G, Williams N, Dave S, Barnfield MC: Extracellular fluid volume and glomerular filtration rate in 1878 healthy potential renal transplant donors: effects of age, gender, obesity and scaling. Nephrol Dial Transplant 2012;27:1429-1437.

16 Holness JL, Fleming JS, Malaroda AL, Warwick JM: (99m)Tc-DTPA volume of distribution, half-life and glomerular filtration rate in normal adults. Nucl Med Commun 2013;34: 1005-1014.

17 Wesson LG: Renal hemodynamics in physiologic states; in Wesson LG (ed): Physiology of the Human Kidney. New York, Grune and Stratton, 1969, pp 96-108.

18 Cirillo M, Laurenzi M, Mancini M, Zanchetti A, Lombardi C, De Santo NG: Low glomerular filtration in the population: prevalence, associated disorders, and awareness. Kidney Int 2006; 70:800-806.

19 De Santo NG, Capasso G, Anastasio P, Coppola S, Policastro M, Bellini L, Massimo L, Pollastro RM, Papalia T, Di Leo VA: Renal functional reserve. Child Nephrol Urol 1991; 11:140-145.

20 Bäck SE, Ljungberg B, Nilsson-Ehle I, Borgå $\mathrm{O}$, Nilsson-Ehle P: Age dependence of renal function: clearance of iohexol and p-amino hippurate in healthy males. Scand J Clin Lab Invest 1989;49:641-646.

21 Pottel H, Hoste L, Dubourg L, Ebert N, Schaeffner E, Eriksen BO, Melsom T, Lamb EJ, Rule AD, Turner ST, Glassock RJ, De Souza V, Selistre L, Mariat C, Martens F, Delanaye $\mathrm{P}$ : An estimated glomerular filtration rate equation for the full age spectrum. Nephrol Dial Transplant 2016;31:798-806.

22 Delanaye P, Mariat C, Cavalier E, Krzesinski JM: Errors induced by indexing glomerular filtration rate for body surface area: reductio ad absurdum. Nephrol Dial Transplant 2009; 24:3593-3596.

23 Lipsey M, Wilson D: Practical Meta-Analysis: Applied Social Research Methods. SAGE Publications, 2001.

24 Vervoort G, Willems HL, Wetzels JF: Assessment of glomerular filtration rate in healthy subjects and normoalbuminuric diabetic patients: validity of a new (MDRD) prediction equation. Nephrol Dial Transplant 2002;17: 1909-1913.

25 Fehrman-Ekholm I, Skeppholm L: Renal function in the elderly ( $>70$ years old) measured by means of iohexol clearance, serum creatinine, serum urea and estimated clearance. Scand J Urol Nephrol 2004;38:73-77.

26 Soares AA, Prates AB, Weinert LS, Veronese FV, de Azevedo MJ, Silveiro SP: Reference values for glomerular filtration rate in healthy Brazilian adults. BMC Nephrol 2013;14:54.

27 Egger M, Davey Smith G, Schneider M, Minder C: Bias in meta-analysis detected by a simple, graphical test. BMJ 1997;315:629-634.

28 Anzures-Cabrera J, Higgins JP: Graphical displays for meta-analysis: an overview with suggestions for practice. Res Synth Methods 2010;1:66-80.

29 Piepsz A, Tondeur M, Ham H: Revisiting normal (51)Cr-ethylenediaminetetraacetic acid clearance values in children. Eur J Nucl Med Mol Imaging 2006;33:1477-1482.

30 Piepsz A, Tondeur M, Ham H: Escaping the correction for body surface area when calculating glomerular filtration rate in children. Eur J Nucl Med Mol Imaging 2008;35:1669-1672.

31 Eriksen BO, Melsom T, Mathisen UD, Jenssen TG, Solbu MD, Toft I: GFR normalized to total body water allows comparisons across genders and body sizes. J Am Soc Nephrol 2011;22:1517-1525.
32 Ma YC, Zuo L, Chen L, Su ZM, Meng S, Li JJ, Zhang CL, Wang HY: Distribution of measured GFR in apparently healthy Chinese adults. Am J Kidney Dis 2010;56:420-421.

33 Davies DF, Shock NW: Age changes in glomerular filtration rate, effective renal plasma flow, and tubular excretory capacity in adult males. J Clin Invest 1950;29:496-507.

34 Soveri I, Berg UB, Björk J, Elinder CG, Grubb A, Mejare I, Sterner G, Bäck SE; SBU GFR Review Group: Measuring GFR: a systematic review. Am J Kidney Dis 2014;64:411-424.

35 Stolz A, Hoizey G, Toupance O, Lavaud S, Vitry F, Chanard J, Rieu P: Evaluation of sample bias for measuring plasma iohexol clearance in kidney transplantation. Transplantation 2010;89:440-445.

36 Brändström E, Grzegorczyk A, Jacobsson L, Friberg P, Lindahl A, Aurell M: GFR measurement with iohexol and 51Cr-EDTA. A comparison of the two favoured GFR markers in Europe. Nephrol Dial Transplant 1998;13: 1176-1182.

37 Agarwal R, Bills JE, Yigazu PM, Abraham T, Gizaw AB, Light RP, Bekele DM, Tegegne GG: Assessment of iothalamate plasma clearance: duration of study affects quality of GFR. Clin J Am Soc Nephrol 2009;4:77-85.

38 Odlind B, Hällgren R, Sohtell M, Lindström B: Is 125I iothalamate an ideal marker for glomerular filtration? Kidney Int 1985;27:9-16.

39 Brochner-Mortensen J: The glomerular filtration rate during moderate hyperglycemia in normal man. Acta Med Scand 1973;194:31-37.

40 Gaspari F, Perico N, Matalone M, Signorini O, Azzollini N, Mister M, Remuzzi G: Precision of plasma clearance of iohexol for estimation of GFR in patients with renal disease. J Am Soc Nephrol 1998;9:310-313.

41 Shock NW: Kidney function tests in aged males. Geriatrics 1946;1:232-239.

42 Barai S, Bandopadhayaya GP, Patel CD, Rathi M, Kumar R, Bhowmik D, Gambhir S, Singh NG, Malhotra A, Gupta KD: Do healthy potential kidney donors in India have an average glomerular filtration rate of $81.4 \mathrm{ml} / \mathrm{min}$ ? Nephron Physiol 2005;101:p21-p26.

43 Jafar TH, Islam M, Jessani S, Bux R, Inker LA, Mariat C, Levey AS: Level and determinants of kidney function in a South Asian population in Pakistan. Am J Kidney Dis 2011;58:764-772.

44 Lindeman RD, Tobin J, Shock NW: Longitudinalstudies on the rate ofdeclinein renal function with age. J Am Geriatr Soc 1985;33:278-285.

45 Malmgren L, McGuigan FE, Berglundh S, Westman K, Christensson A, Åkesson K: Declining estimated glomerular filtration rate and its association with mortality and comorbidity over 10 years in elderly women. Nephron 2015;130:245-255.

46 Pani A, Bragg-Gresham J, Masala M, Piras D, Atzeni A, Pilia MG, Ferreli L, Balaci L, Curreli N, Delitala A, Loi F, Abecasis GR, Schlessinger D, Cucca F: Prevalence of CKD and its relationship to eGFR-related genetic loci and clinical risk factors in the SardiNIA study cohort. J Am Soc Nephrol 2014;25:1533-1544. 